\title{
Pengantar Studi Sosial Politik di Kediri
}

\author{
Oleh: M. Rizki Pratama* \\ *Fakultas Ilmu Sosial dan Ilmu Politik Universitas Kadiri
}

Scholar klasik macam Clifford Geertz (1926-2006) bahkan sudah mendahului para sarjana asli Indonesia untuk mempelajari kebudayaan Jawa melalui potret wilayah di Kediri. Melalui Religion of Java (1960) dan Mojokuto: Dinamika Sosial Sebuah Kota di Jawa (1986), Geertz telah berhasil memotret masyarakat apa adanya, tanpa predeterminasi terlebih dahulu, dengan deskripsi tebal (thick description) teori bahwa masyarakat jawa terbagai dari tiga golongan yaitu santri, abangan dan priyayi tetap menjadi salah teori sosial yang sangat awet dan prediktif. Setelah meninggal pada tahun 2006 banyak yang memuji Geertz sebagai antropolog yang mampu mengkaitkan teori general dan riset lokal, partikularistik dan realitas yang lebih luas (White, 2007). Jejak kaki Geertz di Kediri bahkan memulai perubahan sosial baru seperti munculnya kampung Inggris yang diinisiasi oleh para asisten lokal Geertz. Meskipun hingga hari ini karya Geertz banyak diperdebatkan dan dianggap usang, tidak ada satupun riset tentang Kediri yang mampu mencapai gaung internasional seperti karya Geertz. Tulisan ringkas ini hanya mencoba untuk mendeskripiskan berbagai studi dalam bidang sosial dan politik dengan objek wilayah di Kediri serta potensi untuk melakukan studi lebih lanjut, setidaknya agar memantik diskusi dan bahkan riset yang mampu menjangkau level yang lebih jauh pasca karya Geertz, terutama untuk studi sosial politik yang lebih kritis.

Dinamika sosial dan politik Kediri sebenarnya cenderung tidak terjadi perubahan yang drastis, perubahan yang terjadi relatif inkremental. Kondisi ekonomi yang tetap stabil di berbagai era pemerintahan juga menjukkan bahwa Kediri memang daerah yang sangat kondusif, masyarakat Kediri cenderung cinta damai, jarang muncul karakter kekerasan ke permukaan. Berbagai tesis atas kondusifitas tersebut dapat menjadi riset lanjutan, misalkan apakaha karakter budaya manusia-manusia di Kediri Raya memang sangat menghindari konflik atau enggan pada perubahan. Apakah memang itu ada kaitannya dengan golongan priyayi? Lebih lanjut dengan potensi pendidikan tinggi di Kediri yang mampu menjangkau level nasional sudah seharusnya para peneliti untuk mulai melek pada potensi konflik sosial yang bersifat laten, sangat perlu untuk melakukan studi mendalam tentang peta kerawanan konflik di Kediri akibat geseakan antara pendatang dan masyarakat asli yang seringkali diabaikan. Selain itu sejauh mana pengaruh Islam di wilayah Kediri, karena pada dasarnya banyak sekali pondok pesantren yang ada di Kediri. Bahkan beberapa adalah yang tertua di wilayah Jawa, misalkan pondok Lirboyo. 
Dalam subject matter lain misalkan dari sisi pemerintahan misalkan hadirnya beberapa generasi kepemimpinan di wilayah kediri yang spesifik yaitu Kota Kediri dapat menujukkan perubahan tata kelola kepemimpinan misalkan ketika dipimpin oleh H.A. Maschut yang gemilang karena prestasi di bidang olahraga melalui prestasi Persik Kediri yang merajai liga Indonesia. Prestasi Samsul Azhar yang mampu meningkatkan kualitas kesehatan masyarakat kediri. Dan kini dipimpin oleh Abubakar yang mampu menunjukkan perubahan landscape pembangunan kota kediri lewat program prodamas dan pembangunan berbagai fasilitas publik. Sedikit berbeda dengan wilayah Kabupaten Kediri dengan wilayah yang sangat luas. Dengan kepemimpinan politik yang cenderung masih dipegang oleh rezim yang sama selama 20 tahun terakhir, perubahan-perubahan yang terjadi juga masih kurang radikal. Meskipun baru-baru ini dilakukan kompetisi inovasi desa, sayangnya perubahan yang lebih substantif yaitu tata kelola pemerintahan di Kabupaten Kediri belum terjadi. Semua itu seharusnya dapat dipotret lewat studi-studi yang lebih kritis.

Mungkin beberapa pekerjaan para peneliti yang berkualitas sudah banyak yang menjamah Kediri, terutama dalam beberapa tahun terakhir. Beberapa riset sosial dan politik ramai memperbincangkan Kediri mulai dari yang sangat murni sosiologis hingga terapan misalnya kebijakan publik (Pratama, 2012, 2013). Studi sosial politik kontemporer di Kediri merentang dari pemberdayaan masyarakat (Soewarno \& Vitasmoro, 2018) dan perilaku politik masyarakat (Suwarno, 2017). Selain itu juga muncul riset yang mengungkap relasi antara politik dan santri di Kediri (Susilo \& Suaib, 2017). Dalam bidang kebudayaan Kediri juga mempunyai cerita legenda Panji yang dimaknai sebagai studi sastra (Manuaba, Setijowati, \& Karyanto, 2012). Beberapa studi juga sudah memunculkan elemen kritis seperti kebijakan pembangunan simpang lima gumul yang cenderung elitis (Akbar, 2011). Politik uang dalam pemilihan kepala desa (Amanu, 2015). Perempuan dalam lingkaran politik dinasti (Armoyu, 2013). Studi tentang pengelolaan konflik antar daerah di mana Kediri menjadi salah satu studi kasus juga sudah pernah dilakukan (Setyowati, Sadewo, \& Legowo, 2018). Bahkan scholar internasional seperti Edward Aspinall pernah menggunakan refleksi kasus di Kediri untuk menjelaskan politik uang dan broker dalam pemilihan kepala desa (Aspinall \& Rohman, 2017). Muncul juga studi yang sedikit unik seperti politik dinasti yang selama ini bermakna negatif bahkan setelah diteliti dengan perspektif lain ternyata juga dapat menunjukkan efek positif (Cahyaningtyas \& Affandi, 2015). Studi lain dengan perspektif ekonomi dengan sampel Kediri menunjukkan bahwa politik dinasti cenderung terjadi di daerah miskin (Guritno, Samudro, \& Soesilo, 2018)

Masih banyak hal yang perlu diungkap di Kediri, relasi sosial politik yang cenderung kondusif ditambah dengan berbagai kemajuan daerah sebagai pusat pendidikan tinggi yang perlu diantisipasi kerawanan sosialnya. Selain itu perlu studi yang lebih mendalam dan lebih kritis dalam mengeksplorasi 
kondisi sosial dan politik di Kediri. Seperti mengungkap keberadaan politik dinasti di wilayah Kediri, apakah memang demikian nyatanya, didesain demikian atau justru itu menjadi satu-satunya alternatif yang dimiliki masyarakat Kediri? Hal lain seperti bagaimana dampak pembangunan gaya baru di Kediri, apakah memang dibutuhkan oleh masyarakat? Apakah prioritas pembangunan itu jelas? Tentu kembali kepada harapan untuk melakukan studi lebih lanjut adalah jawabannya. Semoga setidaknya segera muncul riset-riset berkualitas terbaru yang mampu menandingi riset Clifford Geertz tentang Kediri.

\section{Referensi}

Akbar, R. (2011). Local Elites and Development Policy on Simpang Lima Gumul ( SLG ) as a New Town in the District of Kediri. Indonesia Journal of Social Sciences, 3(1), 1-8.

Amanu, M. (2015). Politik Uang dalam Pemilihan Kepala Desa: Studi Kasus di Desa Jatirejo Kecamatan Banyakan Kabupaten Kediri. Mahasiswa Sosiologi, 1(2), 1-23.

Armoyu, M. (2013). Women in the Circles of Political Dynasti. Situbondo.

Aspinall, E., \& Rohman, N. (2017). Village head elections in Java: Money politics and brokerage in the remaking of Indonesia's rural elite. Journal of Southeast Asian Studies, 48(February), 31-52. https://doi.org/10.1017/S0022463416000461

Cahyaningtyas, N., \& Affandi, M. A. (2015). POLITIK DINASTI DI KABUPATEN KEDIRI: “ Pertukaran Sosial Tim Pemenangan Bupati Haryanti -Masykuri dengan Warga Desa Pare Lor Kecamatan Kunjang .” Paradigma, 6(1), 1-8.

Guritno, D. C., Samudro, B. R., \& Soesilo, A. M. (2018). Does Political Dynasty Cause Poverty? JEJAK: Journal of Economics and Policy, 11(36), 429-446.

Manuaba, I. B. P., Setijowati, A., \& Karyanto, P. (2012). Transformasi Cerita Panji dalam Masyarakat Jawa: Studi Berdasarkan Perspektif Kajian Resepsi Sastra Jaussian. Surabaya.

Pratama, M. R. (2012). Program Mobile Public Service Kantor Pelayanan Perizinan Kota Kediri. Yogyakarta.

Pratama, M. R. (2013). Inovasi Pelayanan Publik ( Studi Deskriptif Tentang Nilai Tambah (Value Added ) Inovasi Pelayanan Perizinan Bagi Masyarakat Di Kota Kediri ). Manajemen Dan Kebijakan Publik, 1(2), 218-225.

Setyowati, R. N., Sadewo, F. S., \& Legowo, M. (2018). The Role of Political Communication in Anticipating Social Conflicts Based on the Government Policy in East Java. Advances in Social Science, Education and Humanities Research, 108(SoSHEC 2017), 39-44.

Soewarno, \& Vitasmoro, P. (2018). The Society Empowerment of Religious Recreation in Maria Lourdes Cave to Increase Economy Social Society in Puh Sarang Village Kediri. Journal of Engineering and Applied Sciences, 13(Special Issue 1).

Susilo, S., \& Suaib, E. (2017). Politicians among Santri Examining the Understanding of Political Power among PKB Elites in Kediri City. The Social Sciences, 12(8), 1317-1323.

Suwarno. (2017). The Effects of Culture and Structure of Society on Political Society Behavior. Journal of Arts, Science \& Commerce, 8(4), 1-7. 
White, B. (2007). Clifford Geertz : Singular Genius of Interpretive Anthropology. Development and Change, 38(6), 1187-1208. 